\title{
Influence of citrate buffer and flash heating in enhancing the sensitivity of ratiometric genosensing of Hepatitis $C$ virus using plasmonic gold nanoparticles
}

\author{
Hrishikesh Shashi Prakash ${ }^{1 \dagger}$, Pranay Amruth Maroju ${ }^{1 \dagger}$, Naga Sai Sriteja Boppudi ${ }^{1}$, Aniket Balapure², \\ Ramakrishnan Ganesan ${ }^{2^{*}}$ and Jayati Ray Dutta ${ }^{1 *}$ (i)
}

\begin{abstract}
Gold nanoparticles (Au NPs) based technology has been shown to possess enormous potential in the viral nucleic acid diagnosis. Despite significant advancement in this domain, the existing literature reveals the diversity in the conditions employed for hybridization and tagging of thiolated nucleic acid probes over the Au NPs. Here we employ the probe sequence derived from the Hepatitis C virus to identify the optimal hybridization and thiol-Au NP tagging conditions. In a typical polymerase chain reaction, the probes are initially subjected to flash heating at elevated temperatures to obtain efficient annealing. Motivated by this, in the current study, the hybridization between the target and the antisense oligonucleotide (ASO) has been studied at $65^{\circ} \mathrm{C}$ with and without employing flash heating at temperatures from 75 to $95^{\circ} \mathrm{C}$. Besides, the efficiency of the thiolated ASO's tagging over the Au NPs with and without citrate buffer has been explored. The study has revealed the beneficial role of flash heating at $95^{\circ} \mathrm{C}$ for efficient hybridization and the presence of citrate buffer for rapid and effective thiol tagging over the Au NPs. The combinatorial effect of these conditions has been found to be advantageous in enhancing the sensitivity of ratiometric genosensing using Au NPs.
\end{abstract}

Keywords: DNA hybridization, Flash heating, Citrate buffer, Thiol conjugation, Hepatitis C virus, Gold nanoparticles based DNA sensing

\section{Introduction}

Owing to the innate plasmonic and electronic properties, gold nanoparticles (Au NPs) gained significant attention in several biological applications [1-7]. In the

\footnotetext{
*Correspondence: ram.ganesan@hyderabad.bits-pilani.ac.in; jayati@hyderabad.bits-pilani.ac.in ${ }^{\dagger}$ Hrishikesh Shashi Prakash and Pranay Amruth Maroju authors contributed equally to this work

${ }^{1}$ Department of Biological Sciences, Birla Institute of Technology and Science (BITS), Pilani, Hyderabad Campus, Jawahar Nagar, Kapra Mandal, Medchal District, Hyderabad, Telangana 500078, India ${ }^{2}$ Department of Chemistry, Birla Institute of Technology and Science (BITS), Pilani, Hyderabad Campus, Jawahar Nagar, Kapra Mandal, Medchal District, Hyderabad, Telangana 500078, India
}

context of biosensing, the pioneering work by Mirkin et. al., on ligating the thiol-tagged DNA to Au NPs triggered numerous opportunities [8]. Ever since, the Au NPs turned out to be revolutionary in most of the techniques such as colorimetric, surface-enhanced Raman scattering, electrochemical, spectrophotometric and piezoelectric [9-18]. In majority of these techniques, the efficient hybridization between the thiol-tagged probe and target DNA is crucial. Also, quantitative binding of the thioltagged probe over Au NPs is another important factor for higher efficacy of the assay [19-22].

The citrate-capped Au NPs typically possess a zeta potential in the range of $-30 \pm 10 \mathrm{mV}$, signifying the negatively charged surface nature [23]. DNAs also 
possess similar charge on their backbone due to the negatively charged phosphate moieties [24]. Thus, when the thiol-tagged DNAs were attempted to conjugate with the surface of citrate-capped Au NPs, due to the chargecharge repulsion, the efficacy of the binding was found to be poor $[25,26]$.

To overcome this, salt-aging technique was developed, in which the externally added electrolyte such as $\mathrm{NaCl}$ minimizes the charge-charge repulsion between the citrate units as well as with the phosphate moieties of the incoming DNAs and thereby creating adequate void space for the thiolated DNA to approach the surface of Au NPs [27, 28]. However, the salt-aging process requires $24-48 \mathrm{~h}$ for efficient conjugation [19]. This has been overcome by strategies like tuning the $\mathrm{pH}$ of the $\mathrm{Au}$ NPs using citrate buffers, instant dehydration in butanol (INDEBT), etc. [29, 30]. Such strategies have been found to yield rapid and quantitative thiol conjugation over the Au NPs. Among these, the method that utilizes citrate buffer is highly attractive due to its simplicity and efficiency. It is generally believed that such conjugation conditions are required when more amount of DNA has to be conjugated over the Au NPs and therefore the previous studies focused with high DNA to Au NPs ratio (typically $>20$ ). However, the necessity of citrate buffer for the cases with low DNA to Au NPs ratio has so far not been explored.

Successful hybridization between the probe and target DNA is also critical in biosensing. The degree of hybridization therefore is an important criterion to realize this. There is a vast diversity in the literature with respect to the DNA hybridization conditions. Many reports employ $37{ }^{\circ} \mathrm{C}$ as the hybridization temperature, while adapting the duration as $1-4 \mathrm{~h}$ [30-34]. On the other hand, in an attempt to realize the hybridization at a shorter time, slightly higher temperatures in the range of 55 to $65{ }^{\circ} \mathrm{C}$ are used, while the time was decreased to $20 \mathrm{~min}$ [35-37]. Few literature reports adopt a short-duration of flash heating at $95{ }^{\circ} \mathrm{C}$, followed by hybridization at normal temperatures $[38,39]$. Thus, there exists a significant diverstity in terms of the hybridization conditions.

On a different note, 185 million population is globally affected by the Hepatitis $\mathrm{C}$ virus (HCV), which is a blood-borne pathogen. It is known that the serological diagnosis responds typically 4 to 6 weeks post-infection due to the time required for the production of adequate amount of the antibodies. Contrarily, the molecular diagnostics is preferred, as it is highly sensitive and earlystage detection in 1 to 2 weeks post-infection is possible [36]. Since there is no licensed vaccine available till date, though efforts are undertaken by the researchers [40], the timely detection and diagnosis is imperative, since the undetected and untreated conditions could lead to hepatocellular carcinoma [41]. Therefore, in this current study, we utilized an antisense oligonucleotide (ASO) derived from the core region (conserved region) of the $\mathrm{HCV}$ genome and subjected it to Au NPs based sensing against the viral target using optimal hybridization and citrate-mediated conjugation conditions.

\section{Materials and methods \\ Materials and characterization}

Trisodium citrate and $\mathrm{HAuCl}_{4} \cdot 3 \mathrm{H}_{2} \mathrm{O}$ were procured from Sigma Aldrich, and used as received. The target (5'CGG ATTCGCCGACCTCATGGGGTACATCCCGCTCGT CGGC3'), ASO (5'SH-AAAAAAAAAAGCCGACGA GCGGGATGTACCCCATGAGGTCGGCGAATCCG3'), and control (5'TTACCGATAATCCTCCGGGGCATA ACGAATGCTTATAGGA3') oligos were purchased from Eurofins Pvt Ltd. For reducing the disulfide bond of thiol-modified probe, $100 \mathrm{mM}$ DTT (in $100 \mathrm{mM}$ sodium phosphate buffer, $\mathrm{pH}$ 8.3-8.5) was added at 1:5 ratio and incubated at room temperature for $1 \mathrm{~h}$. Phosphate buffer saline (PBS, 1X) was prepared using $37 \mathrm{mM} \mathrm{NaCl}$, $2.7 \mathrm{mM} \mathrm{KCl}, 10 \mathrm{mM} \mathrm{Na} \mathrm{HPO}_{4}$ and $1.8 \mathrm{mM} \mathrm{KH}_{2} \mathrm{PO}_{4}$. The citrate buffer was prepared by dissolving $25.08 \mathrm{mg}$ of trisodium citrate in $1 \mathrm{~mL}$ of water $(100 \mathrm{mM})$ and the final $\mathrm{pH}$ was adjusted to 3.0 using dilute $\mathrm{HCl}$.

Spectramax ${ }^{\circledR}$ iD3 was employed to follow the UV-visible spectral changes of the Au NPs based genosensing assay. The particle size analysis was performed using the Malvern Zeta sizer instrument.

\section{Au NPs-based genosensing}

The well-known Turkevich method was employed to synthesize the citrate-stabilized Au NPs [42]. The synthesized Au NPs exhibited a strong plasmonic peak at $520 \mathrm{~nm}$ with an average hydrodynamic diameter of $\sim 20 \mathrm{~nm}$. In the case of DNA sensing, the hybridization mixture comprising of $2.5 \mu \mathrm{L}$ of the ASO and $2.5 \mu \mathrm{L}$ of target/control in $2.5 \mu \mathrm{L}$ of the $1 \mathrm{X}$ PBS buffer was taken in a PCR tube. Two conditions were employed for hybridization inside a Thermal Cycler: In one case, the hybridization was carried out at $65{ }^{\circ} \mathrm{C}$ for 20 min without any flash heating and in the remaining cases a flash heating for a short duration at a designated higher temperature $\left(75^{\circ} \mathrm{C}\right.$ for $30 \mathrm{~s}, 85^{\circ} \mathrm{C}$ for $30 \mathrm{~s}$ and $95^{\circ} \mathrm{C}$ for $30 \mathrm{~s} / 60 \mathrm{~s} / 120 \mathrm{~s}$ ) prior to hybridization at $65^{\circ} \mathrm{C}$ for $20 \mathrm{~min}$. To the hybridized mixture, about $50 \mu \mathrm{L}$ of Au NPs was added and the resultant solution was subjected to stability analysis by adding $1.75 \mu \mathrm{L}$ and $2.5 \mu \mathrm{L}$ of $5 \mathrm{M} \mathrm{NaCl}$ solution such that the final $\mathrm{NaCl}$ concentration was $145 \mathrm{mM}$ and $340 \mathrm{mM}$, respectively. The same procedure has also been performed with the addition of $0.75 \mu \mathrm{L}$ of citrate buffer along with the hybridization buffer to ascertain the effect of DNA conjugation over Au NPs. After salt addition, 
the absorbance of the plasmonic peak at $520 \mathrm{~nm}$ and the ratiometric values of absorbances at $700 \mathrm{~nm}$ to $520 \mathrm{~nm}$ $\left(\mathrm{A}_{700 / 520}\right)$ were followed.

\section{Results and discussion}

Initially, a polyacrylamide gel electrophoresis (PAGE) experiment was carried out using a $20 \mathrm{wt} \%$ gel solution to assess the effect of different temperature conditions on the hybridization efficacy between the ASO and target DNA. Figure 1a shows the gel image obtained with $3 \mu \mathrm{M}$ concentration of ASO and target/control DNAs subjected to different hybridization conditions. Two bands corresponding to ASO and control were clearly seen in the case of control experiments that confirmed no hybridization took place between the probe and control. On the other hand, a bright thick single band in the case of target subjected to different conditions revealed efficient hybridization between the ASO and target DNA. Further quantification of the bands corresponding to the hybridized DNA using ImageJ software (Version 1.8.0_172) revealed a 7.5\% higher hybridization efficacy with the sample subjected to a flash heating of $95^{\circ} \mathrm{C}$ for $120 \mathrm{~s}$, as opposed to the sample that was not subjected to any flash heating (Fig. 1b). These results prompted us to probe further the effect of hybridization conditions in the Au NPs based DNA sensing. For this, we chose three conditions such as no flash heating, and $30 \mathrm{~s}$ and $120 \mathrm{~s}$ flash heating at $95{ }^{\circ} \mathrm{C}$. While one set of samples were

\section{a}

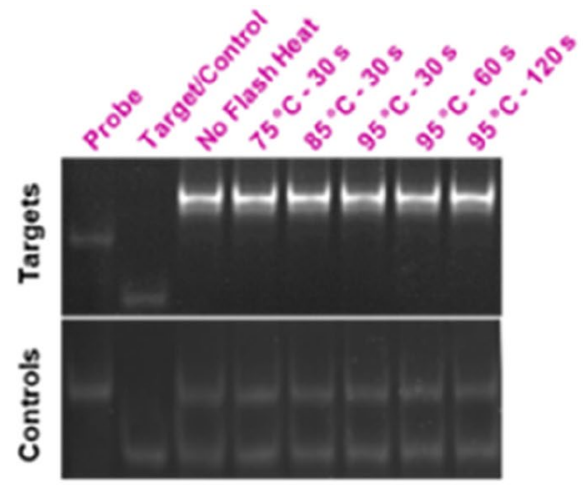

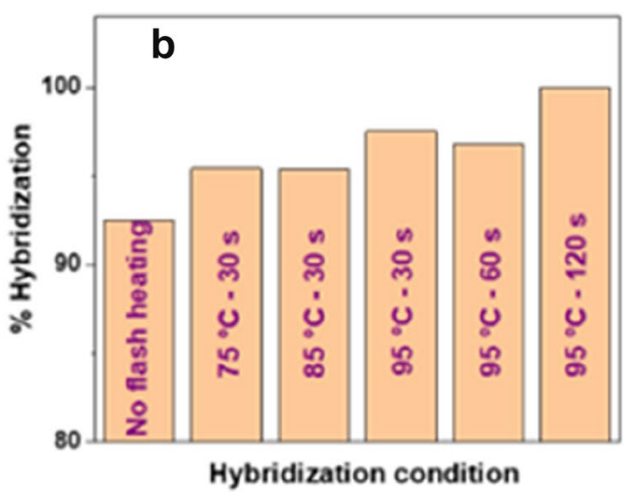

C

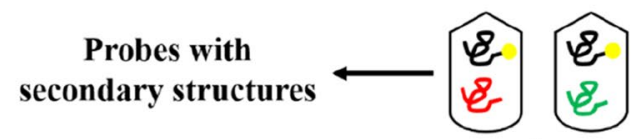

\& $\rightarrow$ Thiolated-probe

\& $\rightarrow$ Target

\& $\rightarrow$ Control
Flash heating followed by hybridization

Unhybridized Control

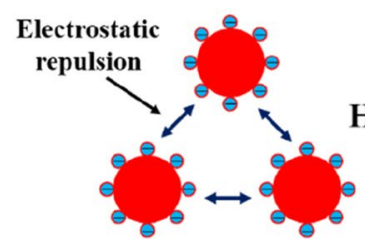

Addition of Hybridization mixes

Citrate capped AuNPs
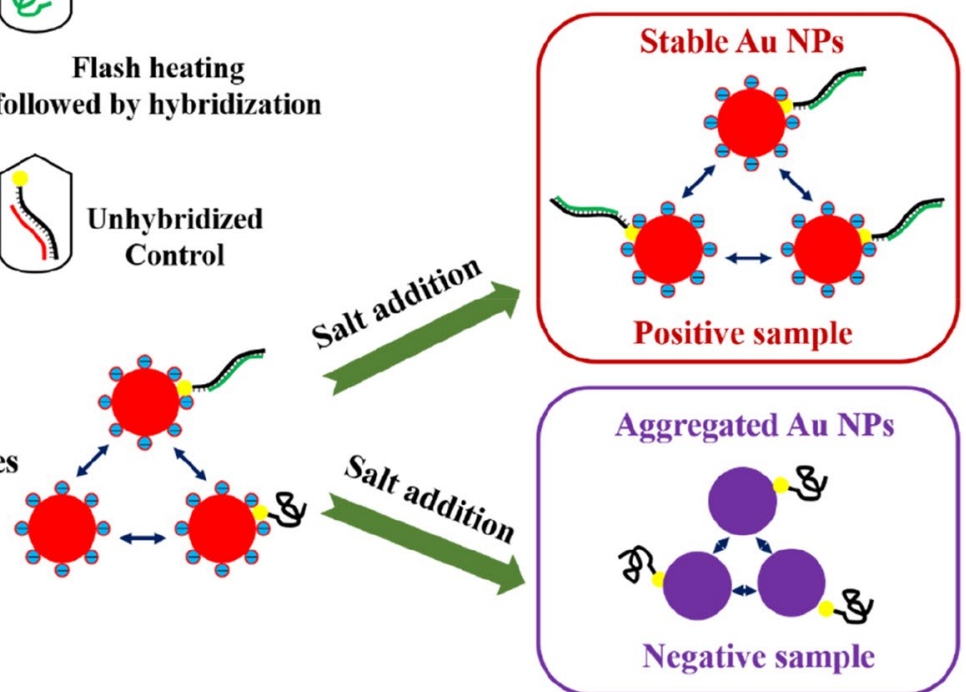

Fig. 1 a Polyacrylamide gel electrophoresis of the probe, target and control DNA subjected to different hybridization conditions and $\mathbf{b}$ the corresponding percentage hybridization quantification using ImageJ software. c Schematic representation on the mechanism of the sensing strategy employed in this study 
subjected to Au NPs based sensing assay to ascertain only the effect of flash heating conditions, another set of samples were subjected to the sensing assay with the addition of citrate buffer in the hybridized mixture as it has been proven to yield rapid and quantitative thiol-conjugation over Au NPs in minutes [29].

The mechanism of the Au NPs mediated sensing assay is based on the following factors. It is known that the stability of the Au NPs is imparted due to the electrostatic repulsion between the negatively charged citrate moieties on the surface. The citrate-stabilized Au NPs synthesized through the Turkevich method exhibit a plasmonic peak at $520 \mathrm{~nm}$ and a relatively low absorbance at wavelengths greater than $650 \mathrm{~nm}$ in the UV-visible spectroscopy. Upon salt addition, due to the masking of electrostatic repulsion between the citrate moieties by the excess of sodium ions, the Au NPs tend to aggregate. The aggregated colloidal Au NPs are known to compromise their plasmonic absorbance and exhibit higher light scattering at longer wavelengths. It is known that the negatively charged DNA enhances the charge density (zeta potential) of the Au NPs upon binding to them. Such an enhancement in the charge density shall enhance the stability of the nanoparticles against the salt-induced aggregation of the Au NPs. Thus, the Au NPs effectively hybridized with the target DNA sequence shall possess higher stability-in comparison to the negative/control sample-and thereby retain the red color arising from the SPR.

In the case of DNA sensing, two different initial concentrations of the ASO, such as 1.5 and $3 \mu \mathrm{M}$ were hybridized with equimolar concentration of the target/ control. Also, two different conditions were employed for the thiol conjugation over the Au NPs before the salting-out process: (i) without the addition of citrate buffer and (ii) with the addition of $0.75 \mu \mathrm{L}$ of citrate buffer. The UV-visible spectral results obtained from the DNA sensing studies are presented in Fig. 2. The absorbance of Au NPs at $520 \mathrm{~nm}$ as well as the ratiometric value of $700 \mathrm{~nm} / 520 \mathrm{~nm}\left(\mathrm{~A}_{700 / 520}\right)$ have been chosen to follow the effect of hybridization conditions on DNA sensing and the absorbance values before and after salting are summarized in Table 1. It can be seen from Fig. 2 that the $\mathrm{Au}$ NPs added with target/control exhibit a high absorbance value at $520 \mathrm{~nm}(>0.4)$ and a low $\mathrm{A}_{700 / 520}$ ratiometric value of $<0.4$. After salt addition, the absorbance of the positive samples (containing target) at $520 \mathrm{~nm}$ gradually decreased with the addition of $\mathrm{NaCl}$ solution, while the $\mathrm{A}_{700 / 520}$ ratiometric value gradually increased. In the case of positive samples, the cut-off values of the absorbance at $520 \mathrm{~nm}$ and $\mathrm{A}_{700 / 520}$ were found to be $>0.26$ and $<0.5$, respectively, which indicate the stable nature of the
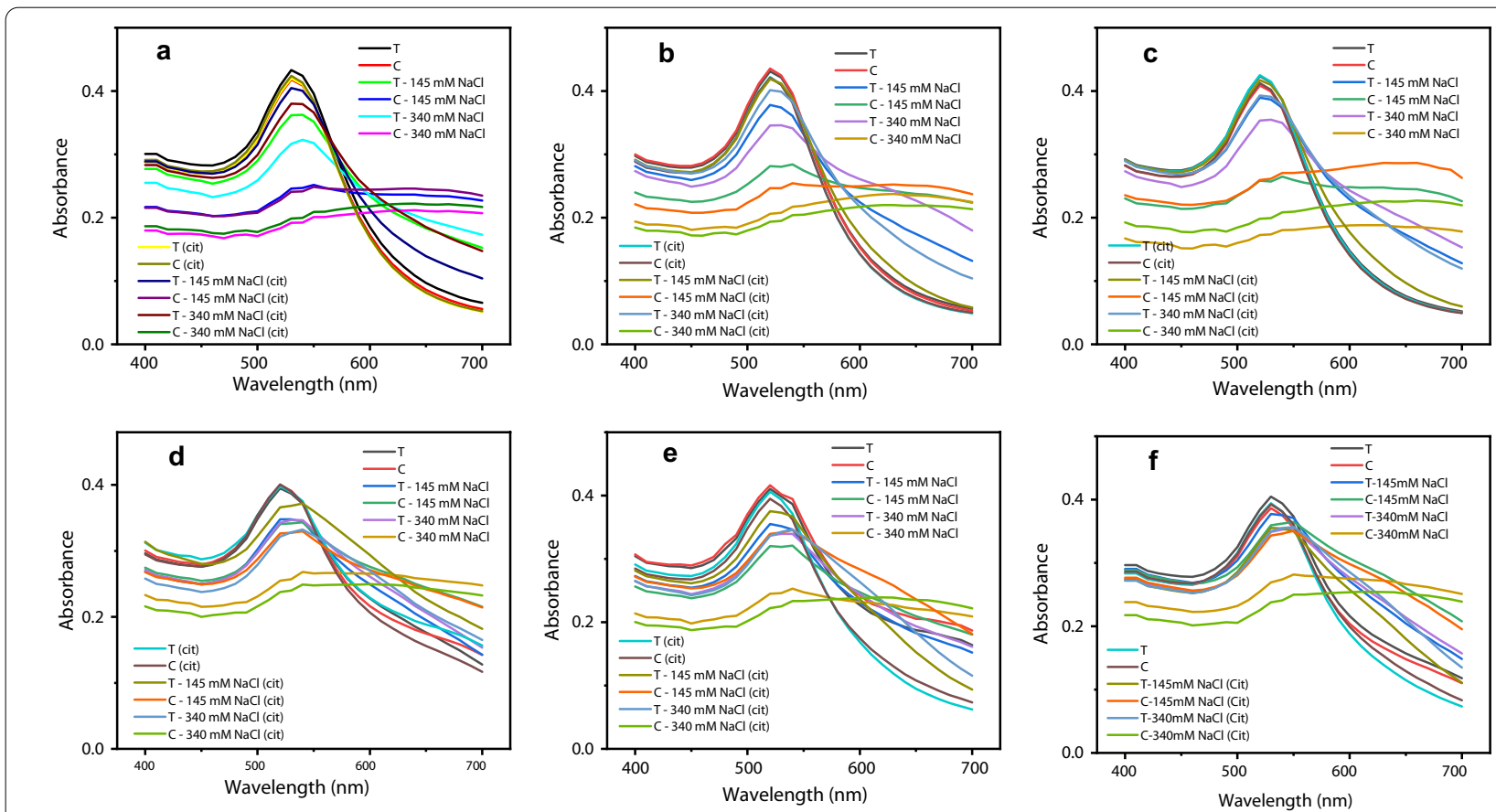

Fig. 2 The UV-visible spectra of the Au NPs added to the oligonucleotides subjected to different hybridization conditions in terms of flash heating: $\mathbf{a}$, d no flash heating, $\mathbf{b}, \mathbf{e} 95^{\circ} \mathrm{C}$ for $30 \mathrm{~s}$, and $\mathbf{c}, \mathbf{f} 95^{\circ} \mathrm{C}$ for $120 \mathrm{~s}$. The top and bottom row experiments were performed with 1.5 and $3.0 \mu \mathrm{M}$ concentrations of the oligonucleotides, respectively. The respective symbols $T$ and $\mathrm{C}$ represent target and control, while the experiments performed with the addition of citrate buffer were coded with (cit). The final concentrations of the $\mathrm{NaCl}$ were also mentioned alongside the sample code 


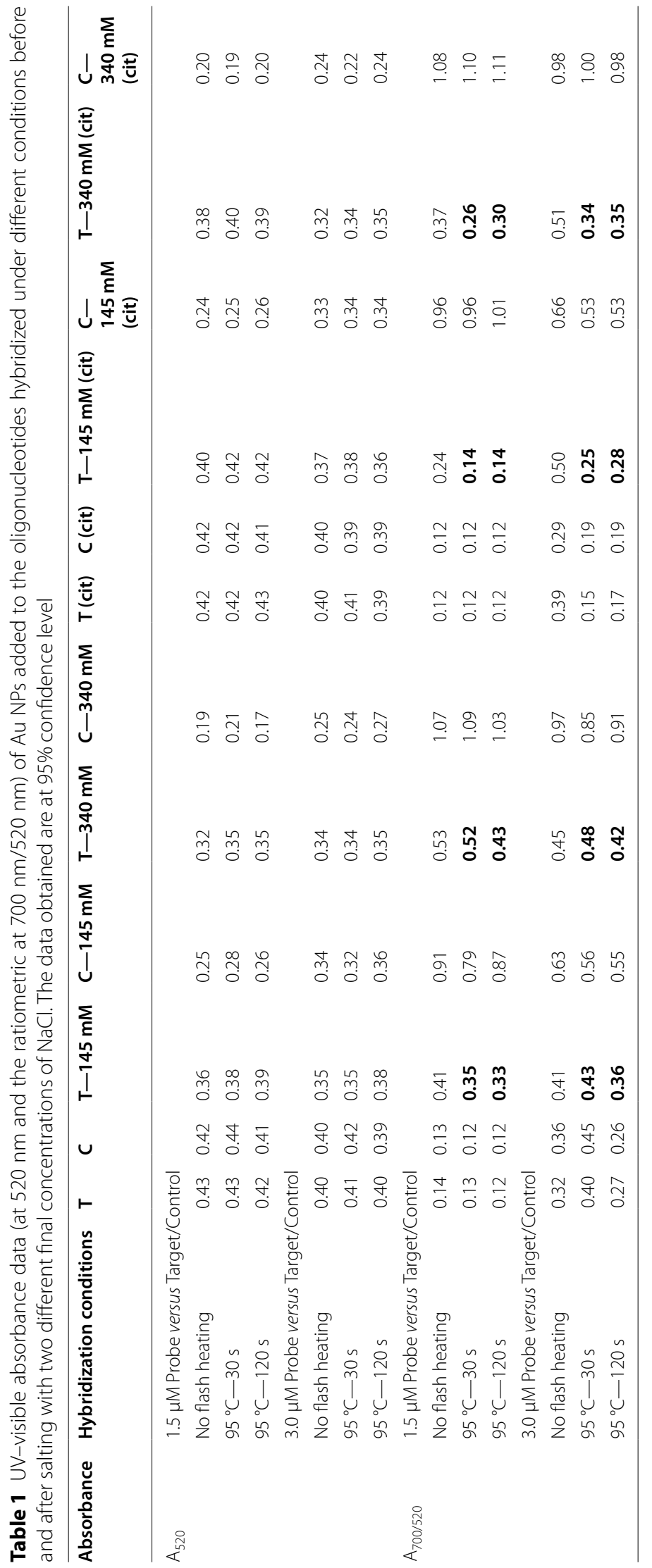


Au NPs. Among the different hybridization conditions employed, the target-ASO hybrids subjected to flash heating were found to have a slightly higher absorbance value at $520 \mathrm{~nm}$ than the no-flash heating sample, though the difference was less (Table 1). On the other hand, a substantial difference was noticed in the ratiometric values of the hybrids subjected to different hybridization conditions. The ratiometric values corresponding to different hybridization conditions have been plotted in Fig. 3.

In general, before the salting process, the absorbance of $\mathrm{Au}$ NPs at $520 \mathrm{~nm}$ was found to be in the range of 0.40 to 0.43 , while the $A_{700 / 520}$ ratiometric values were found to be in the range of 0.15 to 0.4 for all the samples. When 1.75 and $2.5 \mu \mathrm{L}$ of $\mathrm{NaCl}$ was added sequentially (total amount of $\mathrm{NaCl}$ added was $4.25 \mu \mathrm{L}$ ) such that the final salt concentration was 145 and $340 \mathrm{mM}$, the target and control were properly discriminated, as evidenced by the high absorbance value at $520 \mathrm{~nm}$ and low $\mathrm{A}_{700 / 520}$ ratiometric value for the target. It can be seen from Table 1 that the target samples subjected to flash heating exhibited lesser ratiometric values than the ones not subjected to flash heating (highlighted in bold). These results indicate that flash heating does play a positive role in enhancing the hybridization efficacy, which results in better discrimination at the ratiometric values that are often considered to be useful in improving the sensitivity of the assay.

The experiments were then performed with the addition of citrate buffer to ascertain the effect of DNA conjugation over Au NPs and its subsequent effect on the sensitivity of the assay. It was found that the discrimination between the target and control at the ratiometric values was more pronounced when citrate buffer was

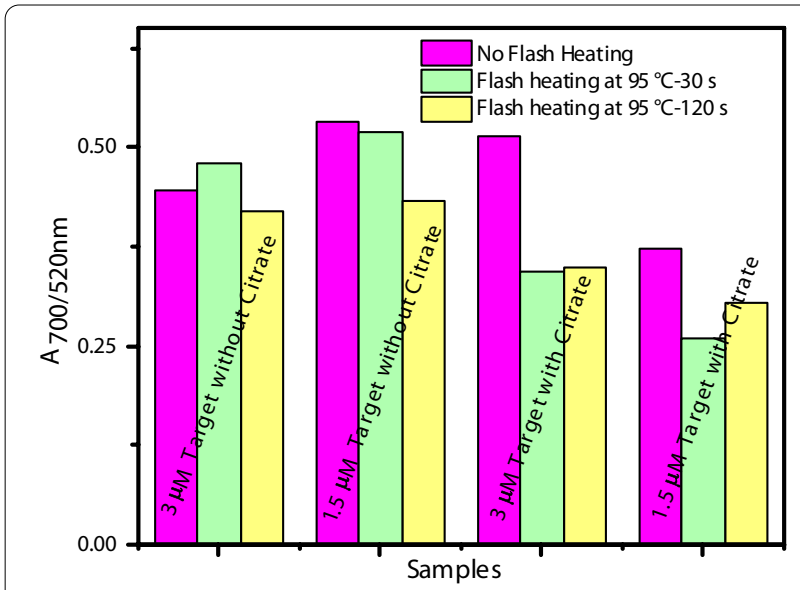

Fig. 3 Plot depicting the $A_{700 / 520}$ ratiometric values of selected samples as a function of different hybridization conditions used. This reveals that the use of citrate buffer is useful in enhancing the conjugation efficiency even when the DNA to Au NPs ratio is as low as 3.5:1, while the available literature reports used a ratio of 20:1 and higher [29].

Since the citrate buffer showed additional benefit in ratiometrically discriminating the samples subjected to flash heating from no-flash heating, their corresponding digital photograph, and dynamic light scattering (DLS) results are presented in Figs. 4 and 5. Although the digital photograph shows the color of the Au NPs used in different assay conditions is indistinguishable to human eyes, the DLS measurements of samples subjected to flash heating revealed a decrease in the particle size after subjecting to the salting-out process, which rationalizes their lower ratiometric values.

The study has revealed the beneficial role of employing a combination of flash heating for efficient hybridization and citrate buffer for rapid tagging of the thiolated DNA over the surface of Au NPs. Such a combination has been found to enhance the sensitivity of the ratiometric absorbance values in the Au NPs based gene sensing. It can be noted that the ratiometric values are highly decisive in discriminating the single nucleotide polymorphism, as described by Sanromán-Iglesias et al. using gold nanoparticles of sizes 13, 46, and $63 \mathrm{~nm}$ [43]. Our study reveals that employing appropriate hybridization conditions can further improve the ratiometric sensitivity of such Au NPs based assays.

\section{Conclusions}

In summary, the effect of hybridization between an ASO and target DNA was ascertained using PAGE experiment, which revealed that the hybridization involving a flash heating of $95{ }^{\circ} \mathrm{C}$ for $120 \mathrm{~s}$, prior to the incubation at $65{ }^{\circ} \mathrm{C}$ for $20 \mathrm{~min}$, resulted in an

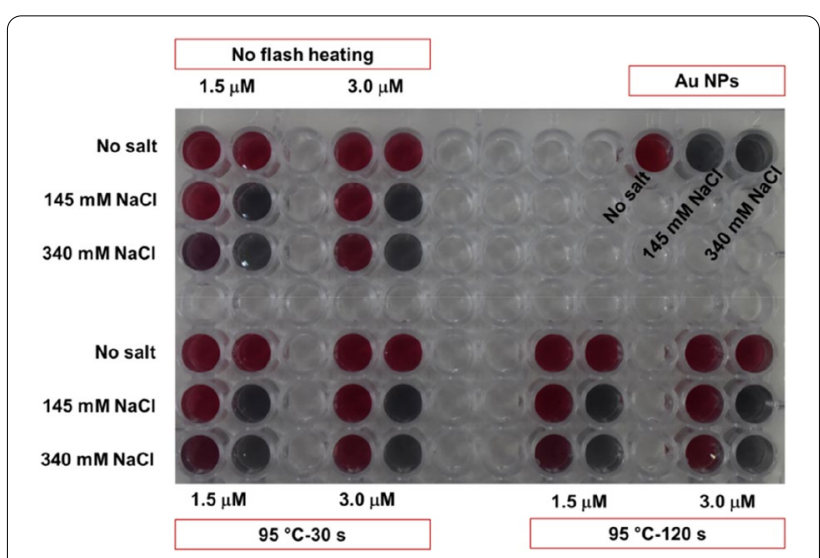

Fig. 4 Digital photograph showing the color of the Au NPs in citrate buffer-added with the target samples subjected to different hybridization conditions-before and after salting-out process 

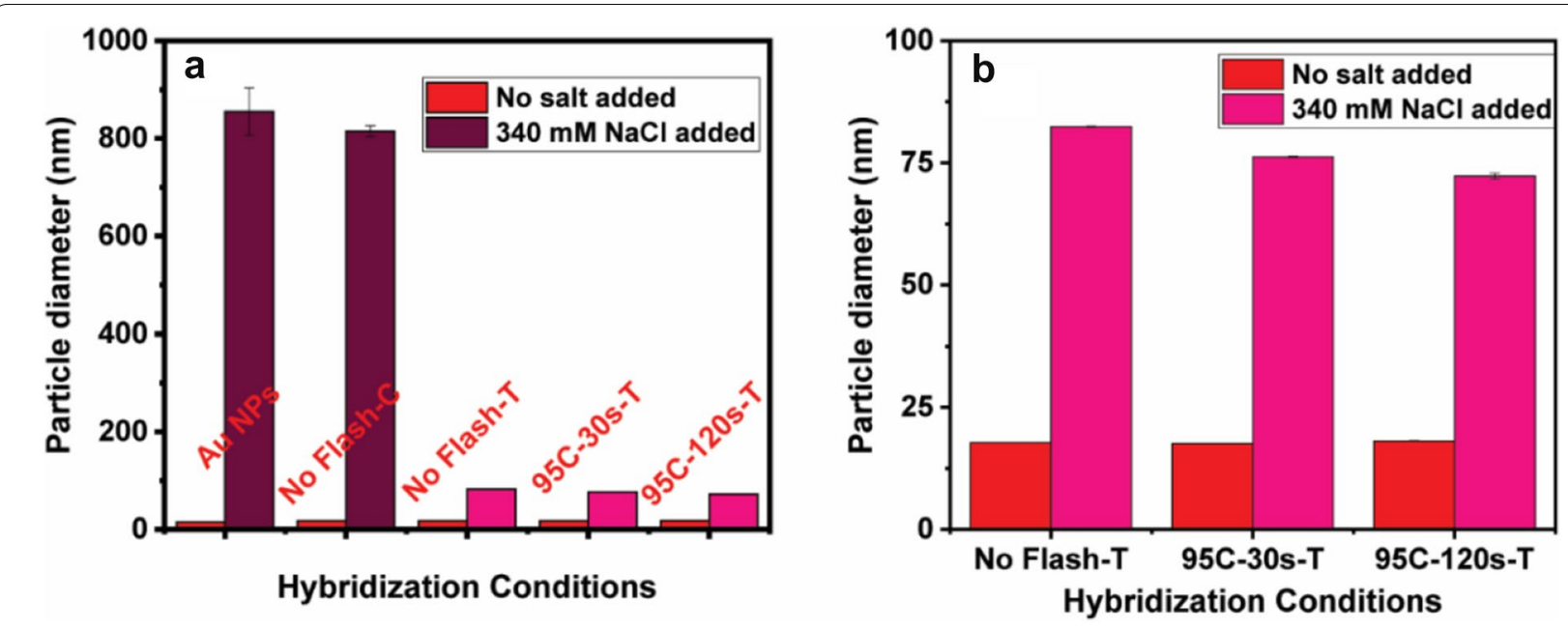

Fig. 5 Effect of particle aggregation measured through the dynamic light scattering analyses over Au NPs in citrate buffer before and after addition of $340 \mathrm{mM} \mathrm{NaCl}$ : a panel showing the effect of salt-induced aggregation over citrate-capped Au NPs, control sample without any flash heating, and target subjected to three different hybridization conditions. The concentration of probe, target (T), and control (C) were fixed as $3 \mu \mathrm{M}$. $\mathbf{b}$ Zoomed in data of the target samples subjected to different hybridization conditions shown in (a)

enhancement in the efficacy to the tune of $7.5 \%$ as opposed to the hybridization condition without the flash heating. The effect was further analyzed in the $\mathrm{Au}$ NPs based DNA sensing to ascertain the usefulness of the flash heating in practical applications. The DNA sensing studies using thiol-tagged synthetic oligonucleotide-derived from the core region of the HCV viral genome-revealed that the ASO-target DNA hybrid subjected to the flash heating stabilized the Au NPs more than the case without flash heating, as evidenced by the lesser ratiometric absorbance values for the former. Furthermore, the use of citrate buffer has shown to be beneficial in the efficient conjugation between the thiolated probe and the Au NPs, even when the DNA to Au NPs ratio is as low as 3.5:1 and 7:1. These results may find potential in employing the appropriate hybridization conditions in the DNA biosensing studies.

\begin{abstract}
Abbreviations
HCV: Hepatitis C virus; Au NPs: Gold nanoparticles; DLS: Dynamic light scattering; DNA: Deoxyribonucleic acid; INDEBT: Instant dehydration in butanol; dsDNA: Double strand Deoxyribonucleic acid; PBS: Phosphate buffer saline; ASO: Antisense oligonucleotide; PAGE: Polyacrylamide gel electrophoresis.
\end{abstract}

\section{Acknowledgements}

The authors thank BITS-Pilani, Hyderabad campus for providing all the infrastructural facilities to accomplish this research work.

\section{Authors' contributions}

HSP: Investigation, Formal analysis, Validation. PAM: Investigation, Formal analysis, Validation. NSSB: Investigation, Formal analysis, Validation. AB: Investigation, Formal analysis, Validation. RG: Conceptualization, Methodology, Resources, Supervision, Writing - review and editing. JRD: Conceptualization, Methodology, Resources, Supervision, Writing - review and editing. All authors read and approved the final manuscript.
Funding

Not applicable.

\section{Availability of data and materials}

The datasets used and/or analysed during the current study are available from the corresponding author on reasonable request.

\section{Declarations}

Ethics approval and consent to participate Not applicable.

\section{Consent for publication}

Not applicable.

\section{Competing interests}

The authors declare no competing financial interest.

Received: 27 Auqust 2021 Accepted: 18 October 2021

Published online: 26 October 2021
References

1. Tabatabaei MS, Islam R, Ahmed M (2021) Applications of gold nanoparticles in ELISA, PCR, and immuno-PCR assays: a review. Anal Chim Acta 1143:250-266. https://doi.org/10.1016/j.aca.2020.08.030

2. Jin H, Sun Z, Sun Y, Gui R (2021) Dual-signal ratiometric platforms: Construction principles and electrochemical biosensing applications at the live cell and small animal levels. TrAC Trends Anal Chem 134:116124. https://doi.org/10.1016/j.trac.2020.116124

3. Li F, Zhou Y, Yin H, Ai S (2020) Recent advances on signal amplification strategies in photoelectrochemical sensing of microRNAs. Biosens Bioelectron 166:112476. https://doi.org/10.1016/.bios.2020.112476

4. Khan I, Vishwakarma SK, Khan AA et al (2018) In vitro hemocompatability evaluation of gold nanoparticles capped with Lactobacillus plantarum derived lipase. Clin Hemorheol Microcirc 69:197-205. https://doi.org/10. 3233/CH-189117

5. Khan I, Nagarjuna R, Ray Dutta J, Ganesan R (2019) Towards single crystalline, highly monodisperse and catalytically active gold nanoparticles capped 
with probiotic Lactobacillus plantarum derived lipase. Appl Nanosci 9:1 101-1109. https://doi.org/10.1007/s13204-018-0735-7

6. Patil S, Chandrasekaran R (2020) Biogenic nanoparticles: a comprehensive perspective in synthesis, characterization, application and its challenges. J Genet Eng Biotechnol 18:67. https://doi.org/10.1186/s43141-020-00081-3

7. De Sio L, Caracciolo G, Annesi F et al (2015) Photo-thermal effects in gold nanorods/DNA complexes. Micro Nano Syst Lett 3:8. https://doi.org/10. 1186/s40486-015-0025-z

8. Wang $\mathrm{D}$, Hua $\mathrm{H}$, Tang $\mathrm{H}$ et al (2019) A signal amplification strategy and sensing application using single gold nanoelectrodes. Analyst 144:310-316. https://doi.org/10.1039/C8AN01474D

9. Nakamura S, Mitomo H, Yonamine Y, ljiro K (2020) Salt-triggered active plasmonic systems based on the assembly/disassembly of gold nanorods in a DNA brush layer on a solid substrate. Chem Lett 49:749-752. https://doi. org/10.1246/cl.200185

10. Ota R, Fukushima Y, Araki Y et al (2020) Ratiometric SERS assays for reliable and automatic quantification of nucleic acids. Chem Lett 50:513-517. https://doi.org/10.1246/cl.200798

11. Mobed A, Hasanzadeh M, Aghazadeh M et al (2019) The bioconjugation of DNA with gold nanoparticles towards the spectrophotometric genosensing of pathogenic bacteria. Anal Methods 11:4289-4298. https://doi.org/10. 1039/C9AY01339C

12. Fournier-Wirth C, Coste J (2010) Nanotechnologies for pathogen detection: Future alternatives? Biologicals 38:9-13. https://doi.org/10.1016/j.biologicals. 2009.10.010

13. Khanna S, Padhan P, Das S et al (2018) a simple colorimetric method for naked-eye detection of circulating cell-free DNA using unlabelled gold nanoparticles. ChemistrySelect 3:11541-11551. https://doi.org/10.1002/slct. 201802671

14. Galdamez A, Serrano A, Santana G et al (2019) DNA probe functionalization on different morphologies of $\mathrm{ZnO} /$ Au nanowire for bio-sensing applications. Mater Lett 235:250-253. https://doi.org/10.1016/j.matlet.2018.10.026

15. Xiao Q, Zheng Y, Liu J et al (2017) Enzyme-antibody dual-film modified gold nanoparticle probe for ultrasensitive detection of alpha fetoprotein Biologicals 47:46-51. https://doi.org/10.1016/j.biologicals.2017.02.008

16. Aura AM, D'Agata R, Spoto G (2017) Ultrasensitive detection of Staphylococcus aureus and Listeria monocytogenes genomic DNA by nanoparticle-enhanced surface plasmon resonance imaging. ChemistrySelect 2:7024-7030. https://doi.org/10.1002/slct.201700779

17. Jin W, Maduraiveeran G (2018) Nanomaterial-based environmental sensing platforms using state-of-the-art electroanalytical strategies. J Anal Sci Technol 9:18. https://doi.org/10.1186/s40543-018-0150-4

18. Lee H, Lee SH (2019) Single to three nucleotide polymorphisms assay of miRNA-21 using DNA capped gold nanoparticle-electrostatic force microscopy system. Micro Nano Syst Lett 7:21. https://doi.org/10.1186/ s40486-019-0100-y

19. Liu B, Liu J (2017) Methods for preparing DNA-functionalized gold nanoparticles, a key reagent of bioanalytical chemistry. Anal Methods 9:2633-2643. https://doi.org/10.1039/C7AY00368D

20. Li F, Zhang H, Dever B et al (2013) Thermal stability of DNA functionalized gold nanoparticles. Bioconjug Chem 24:1790-1797. https://doi.org/10. $1021 /$ bc300687z

21. Mahato K, Nagpal S, Shah MA et al (2019) Gold nanoparticle surface engineering strategies and their applications in biomedicine and diagnostics. 3 Biotech 9:57. https://doi.org/10.1007/s13205-019-1577-z

22. Bhatt N, Huang P-JJ, Dave N, Liu J (2011) Dissociation and degradation of thiol-modified dna on gold nanoparticles in aqueous and organic solvents. Langmuir 27:6132-6137. https://doi.org/10.1021/la200241d

23. Chegel V, Rachkov O, Lopatynskyi A et al (2012) Gold nanoparticles aggregation: drastic effect of cooperative functionalities in a single molecular conjugate. J Phys Chem C 116:2683-2690. https://doi.org/10.1021/jp209 251y

24. Choi J-H, Kim H, Choi J-H et al (2013) Signal enhancement of silicon nanowire-based biosensor for detection of matrix metalloproteinase-2 using DNAAu nanoparticle complexes. ACS Appl Mater Interfaces 5:12023-12028. https://doi.org/10.1021/am403816x

25. Hu M, Yuan C, Tian T et al (2020) Single-step, salt-aging-free, and thiol-free freezing construction of aunp-based bioprobes for advancing crispr-based diagnostics. J Am Chem Soc 142:7506-7513. https://doi.org/10.1021/jacs. 0c00217
26. Lu W, Wang L, Li J et al (2015) Quantitative investigation of the poly-adenine DNA dissociation from the surface of gold nanoparticles. Sci Rep 5:10158. https://doi.org/10.1038/srep10158

27. Storhoff JJ, Elghanian R, Mucic RC et al (1998) One-pot colorimetric differentiation of polynucleotides with single base imperfections using gold nanoparticle probes. J Am Chem Soc 120:1959-1964. https://doi.org/10. 1021/ja972332i

28. Cutler Jl, Auyeung E, Mirkin CA (2012) Spherical nucleic acids. J Am Chem Soc 134:1376-1391. https://doi.org/10.1021/ja209351u

29. Zhang X, Servos MR, Liu J (2012) Instantaneous and quantitative functionalization of gold nanoparticles with thiolated DNA using a pH-assisted and surfactant-free route. J Am Chem Soc 134:7266-7269. https://doi.org/10. 1021/ja3014055

30. Hao Y, LiY, Song L, Deng Z (2021) Flash synthesis of spherical nucleic acids with record DNA density. J Am Chem Soc 143:3065-3069. https://doi.org/ 10.1021/jacs.1c00568

31. Zhang Q, Tian Y, Liang Z et al (2021) DNA-mediated au-au dimer-based surface plasmon coupling electrochemiluminescence sensor for BRCA1 gene detection. Anal Chem 93:3308-3314. https://doi.org/10.1021/acs.analchem. 0 c05440

32. Sun J, Li L, Ge S et al (2021) Dual-mode aptasensor assembled by a WO3/ $\mathrm{Fe} 2 \mathrm{O} 3$ heterojunction for paper-based colorimetric prediction/photoelectrochemical multicomponent analysis. ACS Appl Mater Interfaces 13:3645-3652. https://doi.org/10.1021/acsami.0c19853

33. Wang W, Li X, Tang K et al (2020) A AuNP-capped cage fluorescent biosensor based on controlled-release and cyclic enzymatic amplification for ultrasensitive detection of ATP. J Mater Chem B 8:5945-5951. https://doi. org/10.1039/DOTB00666A

34. Kasturi S, Eom Y, Torati SR, Kim C (2021) Highly sensitive electrochemical biosensor based on naturally reduced $\mathrm{rGO} / \mathrm{Au}$ nanocomposite for the detection of miRNA-122 biomarker. J Ind Eng Chem 93:186-195. https://doi. org/10.1016/j.jiec.2020.09.022

35. Mohammed AS, Nagarjuna R, Khaja MN et al (2019) Effects of free patchy ends in ssDNA and dsDNA on gold nanoparticles in a colorimetric gene sensor for Hepatitis C virus RNA. Microchim Acta 186:566. https://doi.org/10. 1007/s00604-019-3685-1

36. Mohammed AS, Balapure A, Khaja MN et al (2021) Naked-eye colorimetric detection of HCV RNA mediated by a 5' UTR-targeted antisense oligonucleotide and plasmonic gold nanoparticles. Analyst 146:1569-1578. https:// doi.org/10.1039/D0AN02481C

37. Mohammed AS, Balapure A, Khan AA et al (2021) Genotyping simplified: rationally designed antisense oligonucleotide-mediated PCR amplificationfree colorimetric sensing of viral RNA in HCV genotypes 1 and 3. Analyst 146:4767-4774. https://doi.org/10.1039/D1AN00590A

38. Li H, Jie G (2020) A versatile dendritical amplification photoelectric biosensing platform based on Bi2S3 nanorods and a perylene-based polymer for signal "on" and "off" double detection of DNA. Analyst 145:5524-5531. https://doi.org/10.1039/DOAN01040E

39. Wang G, Li J, He Y et al (2020) Establishment of a universal and sensitive plasmonic biosensor platform based on the hybridization chain reaction (HCR) amplification induced by a triple-helix molecular switch. Analyst 145:3864-3870. https://doi.org/10.1039/DOAN00249F

40. Chauhan V, Singh MP, Ratho RK (2018) Identification of T cell and B cell epitopes against Indian HCV-genotype-3a for vaccine development-an in silico analysis. Biologicals 53:63-71. https://doi.org/10.1016/j.biologicals. 2018.02.003

41. Saad F, Gadallah M, Daif A et al (2021) Heparanase (HPSE) gene polymorphism (rs12503843) contributes as a risk factor for hepatocellular carcinoma (HCC): a pilot study among Egyptian patients. J Genet Eng Biotechnol 19:3. https://doi.org/10.1186/s43141-020-00106-x

42. Turkevich J, Stevenson PC, Hillier J (1951) A study of the nucleation and growth processes in the synthesis of colloidal gold. Discuss Faraday Soc 11:55-75. https://doi.org/10.1039/DF9511100055

43. Sanromán-Iglesias M, Lawrie CH, Schäfer T et al (2016) Sensitivity limit of nanoparticle biosensors in the discrimination of single nucleotide polymorphism. ACS Sensors 1:1110-1116. https://doi.org/10.1021/acssensors.6b003 93 
Publisher's Note

Springer Nature remains neutral with regard to jurisdictional claims in published maps and institutional affiliations.

Submit your manuscript to a SpringerOpen ${ }^{\circ}$ journal and benefit from:

- Convenient online submission

Rigorous peer review

- Open access: articles freely available online

- High visibility within the field

- Retaining the copyright to your article

Submit your next manuscript at $\boldsymbol{\nabla}$ springeropen.com 